\title{
SOBRE LA COORDINACIÓN Y LA AMBIGÜEDAD ESTRUCTURAL EN LAS SENTENCIAS
}

\author{
Ma Antonia Martinez Linares \\ Universidad de Alicante \\ antonia.martinez@ua.es
}

\begin{abstract}
Resumen
Este trabajo versa sobre coordinaciones de constituyentes estructuralmente ambiguas que se han extraído de un conjunto de sentencias. Tiene por objeto mostrar cómo el potencial de la coordinación como fuente de ambigüedad estructural se ve incrementado cuando la coordinación de constituyentes se combina con algunas de las pautas constructivas características de los textos jurídicos como la abundancia de nominalizaciones y de sintagmas nominales complejos, el uso de incisos, las oraciones largas e intrincadas o el "exceso" de subordinación.

PALABRAS CLAVE: coordinación de constituyentes, polisíndeton, ambigüedad estructural, ambigüedad jerárquica, lenguaje jurídico.
\end{abstract}

\begin{abstract}
The aim of this paper is to examine how ambiguity may increase in the meaning of a judicial text as a result of the use in language expression of coordinated sentences together with syntactic patterns such as nominalization, complex nominal phrases, long and complex subordinate clauses and digressions, all of them being some well known distinctive features of legal language. Our discussion will be based on a selection of excerpts selected from a sample of sentences.
\end{abstract}

KEY WORDS: phrasal coordination, structural ambiguity, hierarchical ambiguity, juridic/legal language, polysyndeton.

\section{Introducción}

Comúnmente se destacan como rasgos sintácticos del lenguaje jurídico-administrativo, además de un cierto descuido "formal"l (anacolutos, faltas de concordancia, errores de puntuación), algunas tendencias constructivas entre las que figuran: la acumulación de nominalizaciones, "el exagerado uso de incisos" (Alcaraz y Hugues, 2002: 115), la abundancia de subordinaciones, que dan lugar a "sintagmas nominales largos" y complejos, a oraciones de sintaxis intrincada y de "desorbitada extensión" (ibid.), que se combinan en párrafos "largos" y contribuyen a que el texto jurídico resulte oscuro, complejo e incluso, como subrayaba De Miguel (2000), "comunicativamente fallido". No es, pues, extraño que el recurso a la coordinación pueda parecer, para este tipo de textos, "garantía de inteligibilidad" (Alcaraz y Hugues, 2002: 118): es un procedimiento sintáctico que parece "universal", muy productivo "on many different levels of grammatical structure" (Dik, 1968: 1), y de

1 Seria, evidentemente, inadecuado considerar que todos los textos jurídicos adolecen de la "incorrección" que a menudo se achaca al lenguaje jurídico: cada redactor tiene su estilo y, en cualquier caso, los textos jurídicos se diversifican en una pluralidad de géneros con diferentes fines, repercusiones y destinatarios. 
aparente simplicidad, que "los hablantes dominan intuitivamente" (Franchini, 1986: 149) y suele asociarse a la sencillez, a la claridad expositiva.

Así, por ejemplo, es evidente que las dos construcciones coordinadas que figuran en el siguiente párrafo de la Constitución Europea, integradas por constituyentes "paralelos" en su estructura interna ${ }^{2}$, que se siguen, además, de modo inmediato, sin otros elementos que interrumpan el encadenamiento lineal de los miembros de la coordinación, resulta claro, no ambiguo, fácil de interpretar:

(1) La Unión se fundamenta en los valores de respeto de la dignidad humana, libertad, democracia, igualdad, Estado de Derecho y respeto de los derechos humanos, incluidos los derechos de las personas pertenecientes a minorías. Estos valores son comunes a los Estados miembros en una sociedad caracterizada por el pluralismo, la no discriminación, la tolerancia, la justicia, la solidaridad y la igualdad entre hombres y mujeres.

No obstante, al margen de que "la gramática de la coordinación es bastante compleja" (Camacho, 1999: 2637) pese a su aparente simplicidad ${ }^{3}$, no pasa desapercibido que, como a menudo se ha señalado en los estudios lingüísticos, la coordinación es, en el nivel formal, un proceso "insuficiente y ambiguo" (Bobes, 1972: 285), que no aclara "por sí mismo" cuestiones tan relevantes para la interpretación como los constituyentes que integran la construcción coordinada y las relaciones de "dependencia externa" que entabla; es decir, qué función asume, de qué núcleo depende o qué posición ocupa en la estructura de la unidad en la que está integrada.

Cabe recordar a este respecto que una conjunciọn 'simple'4 como y es un índice de coordinación, en cuanto que "marks the fact that something before and something after are the Ics of a larger grammatical form" (Dik, 1968: 51), pero no indica con qué elemento del contexto anterior se coordina el constituyente al que precede. Por ejemplo, en el siguiente texto ${ }^{5}$ :

(2) Se regulan asimismo, en este capítulo, otras cuestiones conexas a la iniciación, como el periodo de información previa, las medidas provisionales para asegurar la eficacia de la resolución, la acumulación de asuntos y la modificación o mejora voluntaria de los términos de la solicitud formulada por los interesados.

2 En la primera construcción coordinada, el hecho de que las unidades nominales libertad, democracia, igualdad, Estado de Derecho y respeto de los derechos humanos no vayan precedidas de determinante invita a considerar que forman, junto con respeto de la dignidad humana, una estructura coordinada que especifica los valores en que se fundamenta la unión. En la segunda, por el contrario, es el hecho de que el pluralismo, la no discriminación etc. sean sintagmas nominales determinados lo que orienta sobre su estatus: integran una construcción coordinada, encabezada por la preposición por, que enumera los valores que caracterizan a la sociedad.

3 Aunque parece regirse por "pocos principios bastante simples" (Jiménez Juliá, 1995: 6), lo cierto es que esos principios aún hoy no están plenamente especificados; de ahí que a veces no sea fácil establecer límites claros entre las coordinaciones que pueden considerarse agramaticales y las que, simplemente, resultan "extrañas" o "disuenan". Por ejemplo, según Franchini (1986: 162), para muchos informantes la secuencia que se incluye a continuación "suena mejor sin la y" y es, por tanto, un ejemplo "raro", pero no llega a considerar que exista una coordinación anómala: Se abre una ya clásica y apasionante interrogante, y que, lamentablemente se ha llevado a veces con cierta causticidad...

4 Se considera que una conjunción es 'simple' cuando no es 'discontinua'; es decir, cuando se sitúa entre los miembros coordinados y no ante cada uno de ellos.

5 Procede de la Ley de Régimen juridico de las Administraciones Públicas y del Procedimiento Administrativo Común. 
la conjunción y señala que la modificación o mejora voluntaria de los términos de la solicitud formulada por los interesados se conecta con, al menos, otro constituyente "of the same type" (Haspelmath, 2000: 1), "in some sense equal" (Carston y Blakemore, 2005: 355), "parallel in certain respects" (Langacker, 1991: 472), pero no sirve, evidentemente, de indicador para determinar si la conexión se establece con los sintagmas nucleados por eficacia y acumulación; si los sintagmas coordinados son los que se estructuran en torno a resolución, acumulación, modificación o mejora; si la construcción coordinada está integrada por col(el periodo de información previa) ${ }_{1}$, (las medidas provisionales para asegurar la eficacia de la resolución) ${ }_{2}$ (la acumulación de asuntos) $)_{3}$ y (la modificación o mejora voluntaria de los términos de la solicitud formulada por los interesados $\left.)_{4}\right)_{\mathrm{cc}}$, o si, por el contrario está constituida por cc((otras cuestiones anexas a la iniciación, como el periodo de información previa) ${ }_{l}$, (las medidas provisionales para asegurar la eficacia de la resolución), (la acumulación de asuntos); y (la modificación o mejora voluntaria de los términos de la solicitud formulada por los interesados) $\left.)_{4}\right)_{\mathrm{cc}}$.

Además, puesto que la coordinación no requiere la adyacencia estricta de los elementos conectados, es obvio que tampoco la disposición de los constituyentes "in some sense equals" integrados en construcciones más amplias resulta determinante para la lectura gramatical de las construcciones coordinadas, aunque ello no obsta para que, en algunos casos, el orden lineal de los elementos puede adquirir, como indicador secundario, cierta relevancia.

En el siguiente texto ${ }^{6}$, por ejemplo:

(3) El artículo 149.1.18 de la Constitución distingue entre las bases del régimen jurídico de las Administraciones Públicas, que habrán de garantizar al administrado un tratamiento común ante ellas; el procedimiento administrativo común, sin perjuicio de las especialidades derivadas de la organización propia de las Comunidades Autónomas y el sistema de responsabilidad de todas las Administraciones públicas.

la expresión nominal el sistema de responsabilidad de todas las Administraciones públicas puede estar coordinada con la organización propia de las Comunidades Autónomas, incluso con otro sintagma más alejado: el procedimiento administrativo común ${ }^{7}$, y no necesariamente con las Comunidades Autónomas, el sintagma que la precede de forma inmediata.

Dadas las características generales asociadas a las construcciones coordinadas, parece claro que no es sino la composición interna de los constituyentes situados "antes" y "después" del coordinador el aspecto lingüístico que se toma, fundamentalmente, como referencia para procesar cuáles son las unidades miembros de la coordinación. Si los elementos enlazados han de asumir "the same semantic, syntactic, and pragmatic functions" (Dik, 1997: 192); si han de mantener "the same external dependency relations" (Blakemore y Carston, 2005: 355) y deben situarse en el mismo "nivel jerárquico" (Franchini, 1986: 34) ${ }^{8}$, asociado a cierta homogeneidad en el plano semántico" (Camacho, 1999: $2645 \mathrm{n}$;

6 Procede asimismo de la Ley de Régimen Jurídico de las Administraciones Pública y del Procedimiento Administrativo Comín.

7 Aunque, en este caso, se requeriría una coma tras las Comunidades Autónomas.

8 A juicio de Franchini (1986: 34), la igualdad de nivel jerárquico y la equivalencia de función sintáctica "son dos cosas esencialmente diferenciadas", aunque quizá la cuestión clave sea qué entendemos por "función sintáctica". 
Jiménez Juliá, 1995: 13); si cada uno de ellos ha de satisfacer las restricciones que imponen los núcleos "on constituents occupying the position of the coordinate structure" (Borsley, 2005: 465), es evidente que "each must have a category and semantic type which is fit for the environment in which the whole structure occurs" (Cormack y Smith, 2005: 401); por tanto, todos los miembros han de ser análogos "in some sense", equivalentes o paralelos "in certain respects" (Langacker, 1991: 472), "regardless of the place they have within the linear sequence" (Dik, 1968: 56).

Por ejemplo, en el siguiente texto, procedente de una sentencia:

(4) Lo probado es que se trata de tres contratos, el segundo de ellos prorrogados, tratándose de contrato de trabajo de duración determinada, de interinidad, datado el 5 de noviembre de 1998, celebrado al amparo del artículo 15 del Estatuto de los Trabajadores, según redacción dada por la Ley 63/97, de 23 de diciembre (BOE 30 de diciembre), para sustituir "a trabajadores con derecho a reserva de puesto de trabajo", de contrato de trabajo de duración determinada celebrado al amparo del artículo 15 del Estatuto de los Trabajadores, según redacción dada por la Ley 63/97, de 26 de diciembre (BOE 30 de diciembre), eventuales por circunstancias de la producción, en el que se releja que éste se concierta como consecuencia de atender circunstancias del mercado, acumulación de tareas o exceso de pedidos, de fecha de 1 de febrero de 2001, y de contrato de trabajo de duración determinada, a tiempo completo, de interinidad... (72/05).

el paralelismo estructural que existe, en un primer nivel, entre los sintagmas destacados en cursiva ${ }^{10}$ indica con claridad", pese a las "subordinaciones" que incorporan, cuáles son los miembros de la construcción coordinada.

Debido precisamente a esa "insuficiencia" en el plano formal, la coordinación está considerada como "a source of several types of structural ambiguity"l2 (Dik, 1968: 226); como un tipo de construcción que a menudo no deja claro si, pongamos por caso, los modificadores y complementos que siguen o preceden a un elemento coordinado inciden en toda la construcción o solo en uno de los elementos enlazados ${ }^{13}$, o que posibilita diversas lecturas gramaticales y, por tanto, diversas interpretaciones, "cuando se acumulan varios coordinadores copulativos en diferentes niveles o cuando los miembros coordinados son muy complejos

9 Si bien aún no pueden considerarse plenamente especificados los criterios para establecer en qué aspectos han de ser análogos, equivalentes o paralelos. Entre otras cosas, según señala Borsley (2005: 465), es difícil establecer con carácter general en qué aspectos han de ser similares los elementos coordinados; todo dependería de que el marco en que se integra la construcción coordinada imponga restricciones más o menos específicas. De manera que "there is no possibility of saying that conjuncts must be identical in specific respects".

10 La cursiva es mía. En adelante, se destacará en cursiva parte de los constituyentes implicados en la coordinación cuando por la longitud o la complejidad del texto resulte aconsejable para una mejor comprensión.

11 Aunque, por otras razones, sea preciso releer el texto para interpretar adecuadamente el esquema de esta unidad sintáctica.

12 Como es sabido, se habla de ambigüedad estructural en las coordinaciones cuando "identical sequences of ultimate constituents [...] correspond to different grammatical descriptions" (Dik, 1968: 227).

13 Por ejemplo, de conformidad con Camacho $(1999,2004)$, la construcción el presunto terrorista y narcotraficante puede tener dos lecturas: una en la que presunto afecta solo a terrorista, de manera que la persona a la que se alude es "probado" narcotraficante; otra en la que el presunto afecta tanto a terrorista como a narcotraficante: igualmente se pueden obtener dos interpretaciones del enunciado En la charla participaron periodistas y atletas de Barcelona en cuanto que de Barcelona podría entenderse solo como complemento atletas o como complemento común al conjunto coordinado: "tanto los periodistas como los atletas eran de Barcelona". 
y largos" (Franchini, 1986: 215) o cuando forman parte de unidades intrincadas en las que "puede resultar arduo" descifrar cuáles son los elementos coordinados y en qué nivel, o en qué función, se ha de situar la coordinación.

Por ello, como suele subrayarse en los estudios sobre la coordinación, la "información extralingüística", el "sentido común", el contexto, el "conocimiento previo" o la "situación" (Dik, 1968; Bobes, 1972; Jiménez Juliá, 1995; Camacho, 2004), resultan en buena medida determinantes para neutralizar las "communicative disturbances" (Dik, 1968: 229) a que podría dar lugar la ambigüedad estructural. Pero tampoco pasa desapercibido el papel que, de cara evitar posibles ambigüedades, adquieren los rasgos lingüísticos ${ }^{14}$ que se vinculan a la equivalencia de los constituyentes o que simplemente orientan sobre los elementos que se enlazan o sobre el nivel en que se ubica la estructura coordinada: las concordancias ${ }^{15}$, las formas verbales ${ }^{16}$, la repetición (o supresión) de preposiciones, la disposición de las unidades, los signos de puntuación...

Véase, por ejemplo, el siguiente texto ${ }^{17}$ :

(5) El régimen jurídico de las Administraciones Públicas debe establecerse desde este concepto y trascender a las reglas de funcionamiento interno, para integrarse en la sociedad a la que sirve como el instrumento que promueve las condiciones para que los derechos constitucionales del individuo y los grupos que integran la sociedad sean reales y efectivos

Es el "sentido común" lo que nos lleva, realmente, a interpretar que los grupos se coordina con el individuo, como propietarios ambos de los derechos constitucionales, pero en el plano sintáctico, en realidad, nada hay que impida agrupar como elementos de la coordinación marcada por $y$, por un lado, los derechos constitucionales del individuo y, por otro, los

\footnotetext{
14 Aun en el caso de que no sean realmente obligados para la gramaticalidad de la construcción.

15 Por ejemplo, en la Ley de Régimen Jurídico de las Administraciones Públicas y del Procedimiento Administrativo Común se dice: "La asistencia y cooperación requerida sólo podrá negarse cuando el Ente del que se solicita no esté facultado para prestarla". El hecho de que el participio requerida esté en singular hace que el alcance de la restricción que aporta resulte confuso, en el plano estrictamente gramatical: puede tener como ámbito solo cooperación, el último elemento coordinado, porque "when two DPs are conjoined" "it is also possible to have partial agreement with the last conjunct, and tipically the adjective has sope over that conjunct as well" (Camacho, 2004: 95); pero es posible también "to have partial agreement with the second conjunct and still have scope over both conjuncts"; por ejemplo, en Auméntase la gracia y caridad humana, aun cuando el adjetivo concuerde en singular se puede interpretar (Camacho, 1999: 2659), que "el adjetivo modifica a la totalidad de la coordinación".

En cambio, en un fragmento anterior del mismo texto se dice que: "[Las Administraciones públicas] deberán prestar, en el ámbito propio, la cooperación y la asistencia activas que las otras Administraciones pudieran recabar"; en este caso, la concordancia en plural del adjetivo activas deja bien claro que se predica tanto de cooperación como de asistencia; que tiene como ámbito no sólo al término más próximo, sino a todo el conjunto coordinado.

16 Cuando, por ejemplo, se coordinan oraciones subordinadas. Así, en Me disgusta que os haya dicho que no viene y que a mi no me haya comunicado nada, interpretamos que el sujeto de me disgista es una construcción coordinada formada por (que os haya dicho que no viene) y (que a mi no me ha dicho nada), no solo porque ambas unidades sean oraciones sustantivas que están encabezadas por que sino también porque llevan el verbo en subjuntivo, el modo que requiere en el sujeto oracional me disgusta como predicado factivo-emotivo. No "leeríamos" en cambio que que a mi no me haya comunicado nada se coordina con que no viene como complemento de haya dicho, pues si bien las dos unidades son oraciones sustantivas el verbo asertivo decir "impone" el modo indicativo en la oración sustantiva complemento y que haya dicho que no viene no cumple ese requisito.

17 Procede también de la Ley de Régimen Juridico de las Administraciones Priblicas y del Procedimiento Administrativo Comín.
} 
grupos que integran la sociedad, de manera que el ser reales y efectivos se entienda como predicado de ambos: las condiciones para que (los derechos constitucionales del individuo) $)_{1}$ y (los grupos que integran la sociedad $\left.)_{2}\right)_{c c}$ sean reales y efectivos.

En cambio, la repetición ${ }^{18}$ de la preposición de ante el segundo elemento coordinado dejaría claro, en el plano sintáctico, cuáles son los miembros de la coordinación y, por tanto, la interpretación: el individuo y los grupos que integran la sociedad son las entidades "sujeto" de los derechos constitucionales: las condiciones para que los derechos constitucionales del individuo y de los grupos que integran la sociedad sean reales y efectivos.

Este trabajo examina una pequeña muestra de coordinaciones, extraídas de un conjunto de sentencias ${ }^{19}$, que pueden considerarse estructuralmente ambiguas o cuya organización sintáctica no resulta, al menos en una primera lectura, clara; el objetivo que se pretende con ello es, simplemente, poner de manifiesto que, dado su potencial como fuente de ambigüedad estructural y dada la relevancia que adquieren ciertos rasgos lingüísticos (además de la información extralingüística) para la lectura adecuada de las construcciones coordinadas, el recurso a la coordinación de constituyentes, cuando se combina con esos rasgos sintácticos típicamente asociados a los textos jurídicos, no siempre resulta garantía de inteligibilidad. Antes bien, puede contribuir a que el texto resulte no solo impreciso, sino también difícil, o al menos "costoso", de interpretar.

\section{A propósito del polisíndeton y la ambigüedad estructural}

Según la definió Dik (1968), la 'ambigüedad jerárquica' es el tipo de 'ambigüedad estructural' que presentan las construcciones coordinadas cuando sus miembros "can themselves be coordinations" y pueden, por tanto, dar lugar a diferentes descripciones gramaticales "corresponding to the different ways in which the members can be hierarchically organized" (Dik, 1968: 230); así ocurre por ejemplo en Han citado a Lola y a Paco y a Anabel, que puede corresponderse con tres lecturas gramaticales distintas:

a) Una lectura "plana" - quizá la "menos natural"-, en la que la coordinación estaría integrada por tres constituyentes situados en el mismo nivel: Han citado( (a Lola $)_{I}$ y (a $\mathrm{PaCO}_{2}$ y (a Anabel $)_{3) \mathrm{cc}}$

b) Otras dos lecturas "jerarquizadas", en las que la construcción coordinada estaría formada solo por dos miembros en un primer nivel, si bien uno de ellos, el primero o el segundo, sería a su vez una coordinación: Han citado co ( (a Lola $)_{I}$ y (a Paco y a Anabel) $)_{2 / \mathrm{cc}}$, Han citado cc ((a Lola y a Paco) , y (a Anabel $\left.)_{2}\right)_{\mathrm{cc}}$.

18 Ha de tenerse en cuenta, sin embargo, que la repetición o no repetición de preposiciones no solo puede actuar como índice desambiguador; también tiene otras repercusiones en la interpretación distributiva o colectiva de la coordinación. Así, por ejemplo, el texto de la Constitución europea establece que El presupuesto deberá ser equilibrado en cuanto a ingresos y a gastos; conforme a la interpretación "distributiva" que se asocia a la repetición de las marcas prepositivas, el texto significaría que "el presupuesto deberá estar equilibrado en cuanto a ingresos y que, asimismo deberá estar equilibrado en cuanto a los gastos"; de no repetirse la preposición, en cambio, habría de entenderse que "debe haber un equilibrio entre ingresos y gastos" (la interpretación a la que nos lleva el "sentido común", dicho sea de paso).

19 Se incluyen algunos ejemplos de sentencias del Tribunal Constitucional (marcadas como TC) y del Tribunal de Justicia (TJ); la mayoría de los ejemplos proceden, no obstante, de sentencias tomadas de la página web de los Servicios Jurídicos de la Universidad de Alicante, procedentes de juzgados de lo contencioso administrativo. 
Aunque, según indicaba Jiménez Juliá (1995: 54), cualquier estructura coordinada de más de dos miembros es susceptible de ambigüedad jerárquica, este tipo de ambigüedad estructural aparece vinculada ya sea a la combinación de conjunciones 'simples', 'no marcadas $^{20}$ ', pertenecientes a clases distintas, como en Deben hacerlo José Luis y Lola o Paco, que combina dos conjunciones 'simples' diferentes (la copulativa y la disyuntiva), ya sea al 'polisíndeton', al uso de una misma conjunción 'simple', 'no marcada', ante cada uno de los miembros de la coordinación excepto el primero, como en Han citado a Lola y a Paco y a Anabel.

Por lo que concierne al uso de coordinadores pertenecientes a clases distintas en una serie coordinada, las lecturas gramaticales se hallan restringidas, según señalaba Dik (1968: 234), por el hecho de que "two different coordinators which are not correlative cannot appear on the same structural level in a single coordination", de manera que en Deben hacerlo Lola y José Luis o Paco no cabe interpretar que los tres elementos coordinados se hallen en el mismo nivel. Pero la construcción, con coordinadores no marcados, es también jerárquicamente ambigua en cuanto que posibilita dos agrupaciones sintácticas distintas, cuyas diferencias afectan a la interpretación de los elementos que presenta como alternativas la conjunción disyuntiva simple $o$ : Deben hacerlo $\left.\mathrm{cc}\left((\text { Lola })_{I} \text { y ((José Luis) o (Paco) }\right)_{2}\right)_{\mathrm{cc}}$, Deben hacerlo cc(((Lola) y (José Luis)) I o (Paco) 2$)_{\mathrm{cc}}$. La ambigüedad desaparecería, en cambio, si en lugar de $o$ se hubiera combinado con $y$ el coordinador discontinuo, de carácter 'marcado' $O . . O^{2 l}$ : dado que "emphatic correlative coordinators [...] cannot but be at the same level of structure" (Dik, 1968: 235), Deben hacerlo o Lola y José Luis o Paco, Deben hacerlo Lola y o José Luis o Paco, solo permiten una lectura, la que sitúa en el mismo nivel, como elementos entre los que se establece la disyunción, los constituyentes, simples o complejos, precedidos de 0 : Deben hacerlo o $\left.\mathrm{cc}\left(((\text { José Luis) y (Lola }))_{1} \text { o }(\text { Paco })\right)_{2}\right)_{\mathrm{cc}}$, Deben hacerlo cc $\left.\left((\text { Lola })_{1} \text { y (o(José Luis) o (Paco) }\right)_{2}\right)_{\mathrm{cc}}$.

En lo que atañe al polisíndeton, a la utilización de conjunciones neutras, como $y$, no solo, según el uso "canónico", ante el último miembro de la coordinación ${ }^{22}$, sino también ante

$20 \mathrm{Si}$, como se dijo antes, el que una conjunción se considere 'simple' se debe a que, desde el punto de vista sintáctico, se sitúa "entre" los miembros coordinados", el que se considere "no marcada' obedece a que, desde el punto de vista semántico, es la más neutra de su clase, la que aporta menos especificaciones semánticas y tiene, por tanto, una distribución más amplia. Así $y$, como conjunción 'no marcada', puede aparecer tanto en entornos afirmativos como negativos Juan y Ana no se han casado, Paco y Pedro me han regalado un libro; es, además compatible con una "interpretación distributiva", que implica que cada uno de los elementos coordinados participó en una acción por separado, como en José Luis y Anabel han comprado libros (cada uno por separado), y con una interpretación colectiva o de "asociación necesaria" (Jiménez Juliá, 1995) que supone que la acción se predica necesariamente del conjunto de elementos coordinados, como en Pamela y José Alberto son una pareja inseparable. $\mathrm{Ni}$, por el contrario, es una conjunción 'compleja', 'marcada', que se puede repetir ante cada uno de los elementos coordinados se restringe a entornos negativos e implica una interpretación distributiva: Ni José Luis ni Anabel han comprado libros, *Ni Pamela ni José Alberto son una pareja inseparable.

21 Según Jiménez Juliá (1995: 85), "o y o...o son dos coordinadores distintos que guardan diferencias básicas en su valor semántico. Frente a $o$, un coordinador simple que "puede expresar tanto la disyunción exclusiva como la inclusiva", o...o es un coordinador complejo que "tiene como valor semántico único la disyunción exclusiva, esto es, la 'contradictoriedad' lógica".

22 No hay que olvidar que la conjunción $y$, además de su papel de conector para indicar indicar "suma", "combinación", "relación", tiene también "the secondary function of indicating that the coordination is (or is to be) terminated" (Dik, 1968: 42); y esa función conclusiva, "de cierre", se da no solo en el marco oracional, sino también en el marco discursivo más amplio. 
otros constituyentes "except the first" (Dik, 1968: 232), cabe recordar, por un lado, que los manuales de gramática lo han venido considerando bien como propio del "habla infantil" -menos frecuente es que se destaque como característica del discurso "no planificado"-, bien como un recurso estilístico que no parece afectar a "la comprensión lógica de lo que decimos" (RAE, 1973: 506) y al que se asocian efectos expresivos muy variados, no muy bien definidos y quizá poco aplicables a autos, sentencias u otros tipos de géneros judiciales: énfasis, relieve subjetivo, afectividad, refuerzo intensificador ${ }^{23}$.

Pero, por otro lado, también se ha señalado en los estudios sobre la coordinación que el empleo de "nexos repetidos" no es solo un caso de variación estilística del uso de un solo coordinador en las coordinaciones múltiples (Camacho, 1999: 2669). Así, mientras el empleo del coordinador no marcado una sola vez ante el último elemento coordinado implica, al menos como interpretación más "natural"24 (Dik, 1968: 233; Borsley, 2005: 467), que todos los miembros de la coordinación se sitúan en el mismo nivel, sin establecer agrupaciones, la repetición puede servir para indicar que alguno de los miembros de una estructura coordinada contiene, a su vez, una coordinación; que, en el interior de la coordinación múltiple, existen "subagrupaciones", coordinaciones, acordes con emparejamientos, distribuciones, relaciones, o grupos conceptuales establecidos por el hablante entre los elementos denotados por los distintos constituyentes. Por ejemplo, en Zapatero y Acebes y Rajoy cruzaron acusaciones en la sesión parlamentaria, la repetición de $y$ viene a indicar que en el conjunto coordinado Zapatero y Acebes y Rajoy hay una subagrupación, que la reciprocidad denotada por cruzar ${ }^{25}$ se establece entre dos miembros: Zapatero por un lado y, por otro, Acebes y Rajoy.

De forma similar, en el texto que se incluye a continuación, procedente de una sentencia:

(6) La sentencia apelada estima que tampoco concurre la infracción alegada por la actora consistente en que el perfil propuesto, acordado e impugnado, no responde a las asignaturas propias de los Planes de estudios de la Universidad de Alicante, pues de la prueba practicada estima que sí existen asignaturas cuya docencia corresponde al Departamento al que viene asignada la plaza, como es el caso de las asignaturas "Sociología General e Industrial" y "Sociología Industrial" (Diplomatura en Relaciones Laborales") y "Sociología de la Desviación (Primer ciclo en Criminología) todas ellas como materias troncales $(777 / 03)$

el uso de $y$ ante cada una de las asignaturas que se mencionan, y no solo ante la que figura en último lugar, vendría a reflejar una "agrupación lógica" de las asignaturas pertenecien-

23 Para la Real Academia (1973: 506), por ejemplo, el polisíndeton consiste en emplear "más conjunciones de las que serían necesarias" para la interpretación del enunciado "por motivos de expresividad, más conjunciones de las que serían necesarias para la comprensión lógica de lo que decimos". Según Gómez Torrego (1997: 232), por poner otro ejemplo, con la repetición de la conjunción "se produce un efecto más expresivo".

24 Para Dik (1968: 234), una construcción como John, Paul, Peter, and Jack "is most naturally interpreted as" (John) (Paul) (Peter) and (Jack), aunque no descarta otras lecturas, como ((John) (Paul) (Peter)) and Jack. Borsley (2005: 467), sin embargo, parece más restrictivo en cuanto a las posibilidades de interpretación. Desde su punto de vista, Hobbs, Rhodes, Barnes and Gunn "do not behave like coordinate structures with two conjuncts and [...] the second and thir conjuncst do not behave like a coordinate structure". En cambio Hobbs, and Rhodes and Barnes "can be a coordinate structure with another coordinate structure as its second conjunct".

25 Con el significado de "Dar, hacer o decir una persona [una cosa] y recibir la misma de [otra persona] (Diccionario Salamanca de la lengua española, Salamanca, Santillana, 1996). 
tes a una misma titulación, si bien todas ellas forman parte de la construcción coordinada que agrupa las asignaturas del departamento vinculadas con el perfil docente asignado a la plaza.

Igualmente, en el siguiente texto:

(7) [...] se acuerda plantear la posible inconstitucionalidad del art. 133, párrafo primero, del Código civil, por vulneración de los arts. 14, 24.1 y 39.1 y 2 CE, así como testimonio de los escritos de alegaciones presentados por las partes y por el Ministerio Fiscal acerca de la pertinencia de plantear la cuestión de inconstitucionalidad (TC 52)

el hecho de que $y$ no aparezca solo ante lo que parece ser el último elemento de una construcción coordinada $-2 C E-$ podría responder a que, dentro de la construcción, se agrupan, formando un constituyente, 14, 24.1. y 39; de manera que, en un primer nivel, está construcción, que especifica los "artículos" objeto de "vulneración", estaría formada por dos miembros: $\left(14,24.1\right.$. y 39.1), y $(2 C E)_{2}$.

En este otro, por poner un ejemplo más:

(8) En conclusión suplica que se dicte Sentencia desestimando el recurso de inconstitucionalidad de referencia. Por otrosí, teniendo en cuenta la evidente conexión entre el objeto de este recurso de inconstitucionalidad y los conflictos de competencia seguidos bajo los números $2832 / 97$ y $541 / 98$ y los recursos de inconstitucionalidad núms. $1172 / 98$ y 1267/99, solicita que se acuerde su acumulación (TC 67)

el. uso de $y$ ante los conflictos... y los recursos viene a sugerir que esos dos sintagmas integran un "grupo lógico" coordinado con el objeto de este recurso. De este modo, la coordinación múltiple introducida por la preposición entre estaría constituida por dos miembros alusivos a las entidades entre las que existe "evidente conexión": (el objeto de este recurso de inconstitucionalidad) y ((los conflictos de competencia seguidos bajo los números 2832/97) y (los recursos de inconstitucionalidad núms. 1172/98 y 1267/99))2.

En cualquier caso, la mera repetición de $y$, sin combinación con otros elementos conectores $\mathrm{u}$ ordenadores correlativos, como por un lado... por otro, o con coordinadores "copulativos" marcados del tipo tanto... como o así como, de uso más restringido ${ }^{26}$ y de sentido distributivo ${ }^{27} \mathrm{o}$ de carácter binario ${ }^{28}$, se considera fuente de 'ambigüedad jerárquica' porque, a diferencia de esos otros elementos, no proporciona, al menos en la lengua

26 Aparte de su condición de nexos "marcados" con sentido distributivo, tienen más restricciones, vinculadas a ese sentido, en relación con los elementos que pueden ir enlazando. Según Camacho (1999: 2671), tanto...como, asi como pueden aparecer con las mismas categorías que $y$ "con la excepción de las oraciones". Franchini (1986: 212) afirman que "tanto... como no puede sino iniciar series, en tanto que asi como solo las termina".

27 Mientras $y$, como conjunción no marcada, permite ambas interpretaciones, tanto... como y así como, como elementos "marcados" para el sentido distributivo, "no pueden aparecer con predicados colectivos" (Camacho, 1999: 2670): *Tanto Ramón como Fernando se encontraron,* Ramón, asi como Fernando, se encontraron.

28 Según Franchini (1986: 210), tanto... como es un conector discontinuo de carácter binario, es decir, solo pueden enlazar dos constituyentes aunque cada uno de ellos pueda ser complejo. Jiménez Juliá (1995), no obstante, parece incluir a tanto...como entre los coordinadores no binarios. En cuanto a así como. Franchini indica que "puede entrar en combinación con el coordinador $y$ precediendo al último miembro" y añade que "este empleo no debe confundirse con el otro, bastante frecuente por cierto, donde así como, debido a su carácter binario, enlaza grupos lógicos. 
escrita $^{29}$, ninguna orientación que permita agrupar inequívocamente, de acuerdo con la intención del hablante, los elementos coordinados.

Así, por ejemplo, en el texto que se incluye a continuación, extraído de una sentencia, el uso del coordinador asi como, de carácter binario", que "sirve de clarificador estructural" y "previene las anfibologías", cuando, como en este caso, hay acumulación de coordinaciones (Franchini, 1986: 211,214), estructura la construcción alusiva a "los informes" que se han de "presentar a la Comisión" en dos constituyentes complejos: uno, los informes anuales sobre gastos y los informes semestrales sobre la evolución de los trabajos; otro, el informe recapitulativo completo de los gastos realizados y el informe final sobre los resultados obtenidos:

(9) [Asume la obligación de] presentar a la Comisión los informes anuales sobre gastos y los informes semestrales sobre la evolución de los trabajos, en el plazo de un mes a partir del final de cada periodo, así como el informe recapitulativo completo de los gastos realizados y el informe final sobre los resultados obtenidos, en el plazo de tres y dos meses, respectivamente, a partir de la finalización la interrupción o el cese de los trabajos financiados por la Comisión (TJ 2001)

En el siguiente, así como establece una "agrupación lógica" entre de las alegaciones de las partes y de la prueba practicada, por un lado, $\mathrm{y}$, por otro, del contenido del expediente administrativo, aunque los tres constituyentes formen la construcción coordinada alusiva a hechos que resultan y de los que ha de partirse para la adecuada resolución del presente litigio:

(10) Para la adecuada resolución del presente litigio ha de partirse de los siguientes hechos, que resultan del contenido del expediente administrativo, así como de las alegaciones de las partes y de la prueba practicada.

En cambio, la sustitución de así como por $y$ en ambos casos no permitiría inferir a qué pauta de agrupación correspondería el polisíndeton desde la perspectiva del redactor ${ }^{30}$.

En este otro, por último, el empleo de estructuradores de la información como de un lado... de otro organiza claramente en dos bloques complejos la coordinación múltiple denotadora de los conceptos que debemos distinguir:

(11) Debemos distinguir, de un lado, la pena principal de cinco meses, con una cuota diaria de 50 euros, así como la responsabilidad civil consistente en el abono a [X] de la cantidad

29 Frecuentemente se señala que, en estos casos, la entonación puede tener un papel desambiguador. Así, por ejemplo, según Jiménez Juliá, "una entonación adecuada, que suele hacer una pausa entre las coordinaciones de nivel más alto" (1995: 54) puede permitir "interpretar adecuadamente estas estructuras".

30 Quedarían como sigue:

(9) [Asume la obligación de] presentar a la Comisión los informes anuales sobre gastos y los informes semestrales sobre la evolución de los trabajos, en el plazo de un mes a partir del final de cada periodo, y el informe recapitulativo completo de los gastos realizados y el informe final sobre los resultados obtenidos, en el plazo de tres y dos meses, respectivamente, a partir de la finalización la interrupción o el cese de los trabajos financiados por la Comisión

(10) Para la adecuada resolución del presente litigio ha de partirse de los siguientes hechos, que resultan del contenido del expediente administrativo, y de las alegaciones de las partes y de la prueba practicada. 
de 1200 euros y la condena al pago de todas las restantes costas de primera instancia, y, de otro lado las dispensas y responsabilidad de neto contenido patrimonial que subsidiariamente para el supuesto de incumplimiento del pago de la multa, se imponen: arresto sustitutorio de setenta y cinco días para el caso de impago (TC 351/04)

Sin embargo, la organización resultaría cuando menos confusa sin el apoyo del estructurador binario $^{31}$.

En realidad, cuando se utiliza solo la repetición de $y$, sin apoyo de otros elementos lingüísticos que orienten sobre la estructura de la coordinación múltiple, únicamente el "sentido común", el "conocimiento previo", "nuestro conocimiento del mundo", el contexto, la situación o el contenido concreto de los elementos coordinados puede guiar la lectura, la "subagrupación", acorde con los emparejamientos, grupos conceptuales, etc., que pudiera tener en mente el redactor.

Así, en el caso de Zapatero y Acebes y Rajoy cruzaron acusaciones en la sesión parlamentaria, es nuestro "conocimiento del mundo", de la situación política, lo que nos lleva a agrupar los constituyentes de la forma en que se ha hecho, pero la construcción posibilita otros ordenamientos; por ejemplo: $c$ ((Zapatero y Acebes) $)_{1}$ y (Rajoy) $\left.)_{2}\right)_{c \text {. }}$.

En el texto (6), es la mención de las titulaciones a las que pertenecen las asignaturas lo que justifica la agrupación; en el texto (8) es el contenido concreto del enunciado en que se integra la coordinación múltiple, así como el contexto precedente ${ }^{32}$, lo que sugiere la "lectura" estructural que se ha hecho, si bien la agrupación podría haber sido distinta atendiendo únicamente a las "marcas estructurales". En cuanto a (7), solo el conocimiento de los artículos mencionados $(14,24.1$ y 39.1 y 2 CE) podría dar sentido a la "jerarquización".

Pero no siempre hay un "conocimiento" compartido entre emisor y receptor u otras indicaciones que permitan inferir qué subagrupación tenía en mente el emisor o que permitan apreciar si, en realidad, el que ha elaborado el texto tenía en mente alguna pauta de jerarquización. ¿Qué agrupación puede colegirse de Han venido Paco y Anabel y Lola para alguien que no conozca a los individuos mencionados y "la situación"? Dada la indefinición de los motivos y efectos del polisíndeton, la repetición del coordinador podría deberse, simplemente, a una falta de planificación que lleva a introducir un elemento, inicialmente no previsto, tras el "cierre" de la construcción.

Así, por ejemplo, en el siguiente fragmento, no resulta en absoluto claro qué intención hay, si es que hay alguna, tras la repetición de $y$ ante en el informe y en la interpretación:

31 Quedaria de esta manera: "Debemos distinguir la pena principal de cinco meses, con una cuota diaria de 50 euros, y la responsabilidad civil consistente en el abono a [x] de la cantidad de 1200 euros y la condena al pago de todas las restantes costas de primera instancia, y las penas y responsabilidad de neto contenido patrimonial que subsidiariamente para el supuesto de incumplimiento del pago de la multa, se imponen: arresto sustitutorio de setenta y cinco días para el caso de impago".

32 Entre otras cosas, en un párrafo anterior se dice lo siguiente: "Por otrosí suplica también que se acuerde la suspensión de su vigencia, de conformidad con el art. 161.2 CE y la acumulación del presente recurso con el conflicto de competencia núm. 541/98, acumulado a los recursos de inconstitucionalidad núms. 1172/98 y 1267/99, conforme dispone el art. 83 LOTC, por guardar la conexión de objeto que justifica la unidad de tramitación y decisión". 
(12) [...] lo que apoya en los acuerdos de la mesa negociadora y en el informe de la Junta de Personal, aportados en la demanda, y en la interpretación de la figura legal del profesor Ayudante y el modelo de plantilla de la Universidad de Alicante (777/03)

Según planteaba Dik, esta ambigüedad jerárquica, relacionada con las posibles subagrupaciones a que pueden dar lugar las coordinaciones múltiples, "may be quite irrelevant" "in actual speech" (1968: 236), al menos cuando se da aislada; en parte porque "the speaker may have no clear intentions in this respect" 33 , en parte porque, aunque el destinatario "may not be able to reconstruct the speaker's intention", esto no tiene necesariamente "any detrimental effect on the establishment of communication". En efecto, aun suponiendo que la repetición del nexo en el texto anterior responda a una intención de establecer grupos conceptuales, no parece que la supresión del primer coordinador afecte de forma decisiva a la interpretación final.

Pero, al margen de que el "uso de nexos repetidos" puede restringir "el conjunto de interpretaciones semánticas posibles" (Camacho, 1999: 2669), es preciso considerar que la posible ambigüedad jerárquica vinculada al polisíndenton puede combinarse, por un lado, con otros tipos de ambigüedad estructural ${ }^{34}$, de mayor repercusión en la "lectura de las coordinaciones".

Por otro lado, como indicaba asimismo Dik (1968: 232), "as de number of coordinated members increases, the number of potential hierarchical ambiguities is correspondingly augmented, not only since more groupings at one structural level become possible, but also because more different levels can be involved". Es evidente, además, que, cuando en la coordinación múltiple se combinan la conjunción copulativa neutra y la disyuntiva, la estructuración, en cuanto que incide sobre las "opciones" denotadas por el coordinador disyuntivo, no resulta en absoluto trivial de cara a la interpretación ${ }^{35}$. De manera que, en

\begin{abstract}
33 Por ejemplo, no parece haber ninguna intención organizativa (al menos clara) tras el uso de la conjunción y ante regula en el siguiente texto, procedente de la Ley de Régimen Juridico de las Administraciones Públicas:"La Ley recoge esta concepción constitucional de distribución de competencias y regula el procedimiento administrativo común, de aplicación general a todas las Administraciones Públicas y fija las garantías mínimas de los ciudadanos respecto de la actividad administrativa". En cualquier caso, no se aprecia una alteración del sentido cuando se suprime esa conjunción.
\end{abstract}

34 Por ejemplo, la ambigüedad 'relacional'. Considérese el siguiente texto, extraído de Ley de Función Pública de la Comunidad Valenciana, que se refiere a las funciones atribuidas al Consejo Valenciano de la Función Pública:" Proponer a la Conselleria de Administración Pública el sometimiento a informe del Consejo Superior de la Función Pública de los anteproyectos de leyes y disposiciones generales en materia de personal que se considere conveniente, así como estudiar y analizar los anteproyectos de leyes y disposiciones estatales y medidas de coordinación que se propongan por dicho Consejo Superior".

La repetición de $y$, unida a la ausencia de determinante ante disposiciones estatales y medidas de coordinación, puede ser un indicador de que existe una subagrupación en la construcción coordinada formada por los anteproyectos de leyes y disposiciones estatales y medidas de coordinación como conjunto sobre el que incide la complementación que se propongan por dicho Consejo Superior, de manera que el texto vendría a significar que es cometido del Consejo Valenciano estudiar y analizar tanto disposiciones estatales y medidas de coordinación que se propongan por dicho Consejo Superior como los anteproyectos de leyes en general, puesto que este constituyente quedaria fuera del alcance de la complementación. Puede ser, sin embargo - y esta parece ser la interpretación más natural según "el sentido común"-, que en la intención del redactor los anteproyectos de leyes también quede restringido por que se propongan por dicho Consejo Superior y que la repetición de y no responda a ninguna subagrupación.

35 Evidentemente, el estado de cosas representado en el enunciado Deben hacerlo José Luis y Lola o Paco es distinto según se interprete como Deben hacerlo((Lola), y (José Luis o Paco)2), o como Deben hacerlo ((Lola y José Luis) I O (Paco)2. 
ausencia de "conocimientos previos" compartidos o de "información extralingüística" suficiente, la combinación de todos estos factores puede dificultar enormemente la "lectura" de las coordinaciones y puede, en consecuencia, afectar a la interpretación.

Por ejemplo, en el fragmento de sentencia que se incluye más abajo la repetición de $y$, que podría hacer pensar en diversos ordenamientos, unida a la combinación con el nexo disyuntivo $o$, hace dificil, cuando menos, entender qué es realmente lo que se está pidiendo, puesto que en una primera lectura no se puede colegir fácilmente entre qué acciones concretas se ha de "elegir", entre qué elementos se establece la disyunción que señala el coordinador $o$ :

(13) [Solicitando] se anule la puntuación por cursos de formación valorándose a todos los concursantes con cero puntos o, en su defecto, se repita la valoración de los méritos por formación computándose exclusivamente los cursos contenidos en el plan de formación de 1995 contenido en la RPT de 1996 y se reconozca al recurrente dos puntos por méritos específicos y se anule la puntuación por méritos específicos a todos los demás concursantes y se anule las puntuaciones de la entrevista ordenando su nueva práctica conforme a lo previsto en el artículo $20.1 \mathrm{~d}$ ) del Decreto 33/99 del Gobierno Valenciano (137/03).

¿Se solicita que se anule la puntuación o en su defecto todo lo demás? ¿Se establece la disyunción solo entre se anule la puntuación y se repita la valoración de méritos dándose por "solicitado" todo lo demás? ¿Se unen se repita... y se reconozca como una opción conjunta frente a se anule la puntuación? ¿Se han de vincular, por el contrario, se reconozca al recurrente dos puntos por méritos especificos y se anule la puntuación por méritos especificos a todos los demás concursantes? Y no se agotan con estas las posibilidades de organización interna de esta múltiple coordinación.

Asimismo la repetición de $y$ contribuye en buena medida a la dificultad de interpretación que presenta el siguiente fragmento, motivada, entre otras razones, por la mezcla de la ambigüedad jerárquica con otras posibilidades de ambigüedad estructural:

(14) La irregularidad formal que supone la falta de publicación, reconocida por la Universidad, de las calificaciones parciales, y el reconocimiento por parte de la actora del conocimiento de los resultados parciales, pese a la falta de publicación y el reconocimiento expreso de que tales actuaciones son previas al Procedimiento de Revisión y Reclamación de Calificaciones, que es el que se somete a revisión y dado que la demandante hizo uso del Procedimiento de Revisión y Reclamación de Calificaciones, y que las notas definitivas de la asignatura fueron publicadas, no permite apreciar que la irregularidad formal cometi$\mathrm{da}$, haya dado lugar a actuaciones que puedan considerarse suficientes para entender que la supuesta inseguridad aducida por la actora puedan influir en el proceso [...] (122/03).

Ha de suponerse que la irregularidad formal se coordina con el reconocimiento por parte de la actora, pero ¿con qué se une el reconocimiento expreso? ¿Se trata de una mera repetición de nexo y se enlaza, por tanto, con la irregularidad formal y el reconocimiento por parte de la actora? ¿Se enlaza, por el contrario, con la falta de publicación? Obsérvese que el tratamiento de la concordancia sujeto- verbo (no permite apreciar) no contribuye precisamente a clarificar la posible ambigüedad estructural, dado que implica un sujeto "singular". 
Tampoco, por existir distintas coordinaciones que permiten interpretar tanto una repetición de nexos como la existencia de coordinaciones en diferentes niveles estructurales, resulta muy claro el siguiente texto en el que "se solicita":

(15) Que se declare la sustitución de los vocales de la Comisión D.[X], D. [Y] y D. [Z], por sus correspondientes suplentes (...) para que sean tales sustitutos, junto con los miembros de la comisión no sustituidos los que formulen nuevos criterios para adaptarse al perfil y para que en los informes previos y en los informes posteriores a la prueba y en resolución a la propuesta de provisión o no provisión incluyan una motivación suficiente y clara ajustada al perfil, a los criterios de evaluación de las pruebas adaptadas al perfil docente, y se eliminen los juicios sobre el proyecto investigador y sobre un pretendido perfil investigador inexistente basado en una visión del área de la Matemática aplicada muy restringida y prosigan el concurso hasta emitir una nueva propuesta de provisión o no provisión ajustada a derecho (321/04).

Tras leer el texto cabe preguntarse, cuando menos, ¿a qué se une y prosigan? Dado que los constituyentes coordinados han de ser análogos o paralelos "in certain respects"; que cada uno ha de satisfacer las restricciones que impone el entorno en que se integra la construcción coordinada, la interpretación más lógica podría ser que prosigan se coordina con incluyan en una construcción final (para que incluyan y prosigan) coordinada, a su vez, con para que sean tales sustitutos...: ambos predicados están en subjuntivo, como requiere una oración final, y, si bien no hay un sujeto léxico expreso, la tercera persona del plural hace posible interpretar que comparten un sujeto explícito en la primera oración final del conjunto coordinado: tales sustitutos; pero, en ese caso, ¿a qué se une y se eliminen, una construcción pasiva refleja que no comparte sujeto con incluyan y prosigan? Por la forma refleja y el modo subjuntivo (dependiente de un predicado de influencia) podría ser: que se declare... y se eliminen, pero en ese caso habría de volverse a la pregunta inicial: ¿a qué se une y prosigan?

\section{Sobre la ambigüedad estructural, la disposición de los constituyentes coordinados y otros "indicadores" linguísticos}

Quizá porque puede resultar "less trivial" (Dik, 1968: 236) que la 'ambigüedad jerárquica', el tipo de 'ambigüedad estructural' al que más atención se ha prestado en los estudios sobre la coordinación, así como en los que versan sobre los lenguajes de especialidad, es el tipo que Dik identificaba como 'relacional'36, asociado al alcance de los modificadores y complementos sobre toda la coordinación o sobre alguno de sus miembros. Por ejemplo, en los siguientes fragmentos procedentes de textos normativos ${ }^{37}$ :

36 En términos de Dik (1968: 236), "there is relational ambiguity with respect to coordination if there is a constituent (or a group of constituents) which may either contract a grammatical relation with a proper subset of the coordinated members, or with all coordinated members separately, or with the unit constituted by de coordination".

37 El texto (16) Procede del texto refundido de li $L$ coy de la función pública valenciana, aprobado por el decreto legislativo de 24 de octubre de 1995. En cuanto a (17), está extraido de la Ley 30/92 de Régimen Jurídico de las Administraciones Ptiblicas y del Procedimiento Administrativo. 
(16) [Corresponde al Gobierno Valenciano] aprobar los proyectos de ley y los decretos en materia de personal, función pública y sistema retributivo.

(17) [...] salvo en lo que afecte a los supuestos de excepción del derecho de acceso a archivos y registros administrativos.

podría existir - si atendemos solo a las posibles lecturas gramaticales - una ambigüedad estructural de este tipo: en (16), en materia de personal, función pública y sistema retributivo podría entenderse como complemento común a los elementos coordinados (los proyectos de ley y los decretos) o como complemento de uno solo de los miembros coordinados: los decretos, de manera que la restricción semántica que implica ese complemento no afectaría a la extensión de los proyectos de ley; otro tanto sucede en (17) con la especificación aportada por administrativos: podría tener un alcance amplio, sobre archivos y registros o solo sobre registros.

No suele prestarse tanta atención, sin embargo, al hecho de que una misma secuencia de constituyentes con marcas de coordinación integrada en una construcción más amplia puede dar lugar a dos o más descripciones gramaticales que difieren en la propia composición de la construcción coordinada y en las relaciones de dependencia externa que entabla; es decir, en el elemento del que depende sintácticamente la coordinación y al que aporta su función semántica.

Tal es el tipo de ambigüedad que, de conformidad con Bobes (1972: 298-299), se desprende de una construcción como una efusión hecha de poder de olvido, de inconsciencia y de ilusiones: no se puede establecer con nitidez si los distintos términos introducidos por la preposición de "son coordinados entre sí o subordinados"; es decir, no queda claro si la coordinación se establece entre los complementos de poder o entre los complementos de hecha; cualquiera de los dos análisis sería válido, pues, por su clase semántica y su categoría, de inconsciencia y de ilusiones están igualmente capacitados para coordinarse con de olvido o con de poder en ambos entornos sintácticos ${ }^{38}$.

No faltan en las sentencias analizadas muestras de este tipo de ambigüedad, asociado al hecho de que existan, en el contexto que precede a la conjunción, dos o más constituyentes capacitados, por su estructura interna, para relacionarse con núcleos distintos y para ser miembros de la coordinación.

Considérese, por ejemplo, el siguiente fragmento:

(18) [...] que sólo pueden ser revisados por el órgano administrativo o jurisdiccional competente en lo que afecta a sus "aledaños", que incluye (sic) todo lo relativo a la vulneración de los principios constitucionales de igualdad, mérito y capacidad en el acceso a la función pública, a la arbitrariedad y a la desviación de poder (136/04)

Puesto que a la arbitrariedad y a la desviación de poder, son sintagmas nominales precedidos de la preposición $a$, se podría interpretar que forman junto con a la función pública una

38 Es asimismo la clase de ambigüedad estructural a que podían dar lugar los textos (2) y (3), puesto que la composición de los constituyentes permitía varias estructuraciones gramaticales con los cambios consiguientes de interpretación, aunque por "sentido común" o por otros factores contextuales algunas de las lecturas potenciales fuesen desechadas. 
construcción coordinada que funciona en el enunciado como complemento de acceso: en el acceso cc ((a la función pública) $)_{1}$, (a la arbitrariedad2) y (a la desviación de poder $\left.)_{3}\right)_{\mathrm{cc}}$. Es más, el hecho de que los tres sintagmas se sigan de forma inmediata nos podría llevar a esa lectura en primera instancia. Pero también cabe deducir de la estructura que la coordinación se establece en otro nivel, que los elementos que integran la construcción coordinada son a la vulneración de los principios constitucionales, a la arbitrariedad y a la desviación de poder, tres sintagmas, también introducidos por $a$, que especifican ese todo incluido en los aledaños: que incluye todo lo relativo cc((a la vulneración de los principios constitucionales de igualdad, mérito y capacidad en el acceso a la función pública), (a la arbitrariedad) 2 y (a la desviación de poder) $\left.)_{3}\right)_{\mathrm{cc}}$.

Estamos, por tanto, ante una construcción estructuralmente ambigua debido a la estructura interna de los constituyentes implicados, si bien, el contenido concreto de los sintagmas y, sobre todo, el "sentido común" pueden, en este caso, mitigar las "perturbación" comunicativa que podría ocasionar la ambigüedad: no resulta lógico interpretar que los miembros de la construcción coordinada sean a la función pública, a la arbitrariedad y a la desviación, como complementos de acceso, porque no parece de "sentido común" que figure entre los principios constitucionales la igualdad, mérito y capacidad en el acceso no solo a la función pública, sino también a la arbitrariedad y a la desviación de poder. Por tanto, la primera de las lecturas sugeridas ha de ser rechazada.

No obstante, como ya se sugirió anteriormente, no siempre el "sentido común" o la información extralingüística son suficientes para deshacer la ambigüedad cuando, como puede suceder en el caso de las sentencias, un destinatario no especialista se enfrenta a un texto especializado. Por ejemplo, para un lector común, no especialista, no resulta fácil entender el fragmento de sentencia que se incluye a continuación, en parte porque en una primera lectura no queda claro con qué se coordina la subsanación de dicha eventual falta de motivación a través de la Sentencia del Tribunal del Jurado, si bien, por tratarse de un sintagma nominal con determinante, ha de entenderse que debería enlazarse con otro sintagma nominal de características similares, como la valoración de la prueba o la valoración probatoria:

(19)Vulneración de derecho a la tutela judicial efectiva (art. 24.1 CE) por incongruencia omisiva, con fundamento en que la Sentencia de casación no dio respuesta explícita ni implícita a las infracciones de doctrina constitucional denunciadas en el cuarto motivo de casación sobre la existencia de motivación suficiente del veredicto, en lo relativo a que en el presente caso había concurrido prueba directa, dispensadora de la necesidad de hacer explícita la valoración de la prueba, o motivación implícita, por resulta obvia la valoración probatoria, $\mathrm{o}$, en su caso, la subsanación de dicha eventual falta de motivación a través de la Sentencia del Tribunal del Jurado, redactada por el Magistrado-Presidente (TC 246/2004).

Por otro lado, ha de tenerse en cuenta que el papel "orientador" de las lecturas que, como se dijo anteriormente, asumen los rasgos formales vinculados a la equivalencia de las unidades enlazadas (como las formas verbales cuando se coordinan oraciones subordinadas) u otros "indicadores" lingüísticos, como la disposición lineal de los constituyentes, o la distancia, puede verse mermado si el texto se caracteriza por la extensión y intrincación sintáctica de las oraciones o por un cierto descuido en el empleo de los rasgos formales. 


\subsection{La disposición de los constituyentes coordinados}

Si bien es cierto que la equivalencia o el paralelismo ("en ciertos aspectos") de los constituyentes coordinados domina, sobre la mera disposición lineal, en el procesamiento de las estructuras, tampoco puede obviarse que, como se indicaba al principio, el orden secuencial puede adquirir, como indicador secundario, cierta relevancia ${ }^{39}$ cuando, por ejemplo, la estructuración interna y el significado de los constituyentes que preceden a la conjunción no proporcionan base suficiente para evitar una posible ambigüedad estructural. Dado el orden secuencial que se sigue en el procesamiento de las oraciones, dadas las restricciones que impone la memoria y dada la tendencia, basada en principios cognitivos ${ }^{40}$, a interpretar como relacionadas conceptualmente las entidades que se sitúan próximas en la codificación, parece claro que la lectura adecuada de los integrantes de la construcción coordinada se ve facilitada cuando, como sucedía en el texto (1), los constituyentes coordinados se siguen de modo inmediato o cuando la coordinación se establece con el primer elemento "paralelo" anterior al coordinador. Por el contrario, la lectura se hace más "costosa" cuando los constituyentes que integran en un primer nivel la construcción coordinada se hallan separados, y la ambigüedad se ve incrementada si las complementaciones que se sitúan entre los miembros potenciales de la coordinación contienen otros elementos que se asemejan en su estructura interna y, por tanto, en sus posibilidades de "distribución".

Así, el enunciado He pedido una hipoteca y un préstamo para pagar unas vacaciones, no resulta equívoco en lo que concierne a la interpretación de lo solicitado: una hipoteca y un préstamo, dos sintagmas nominales, capacitados para funcionar como complementos directos, que se siguen de modo inmediato. En cambio He pedido un préstamo para pagar unas vacaciones y una hipoteca puede resultar equívoco, puesto que entre una hipoteca y un préstamo existe otro sintagma nominal, unas vacaciones, que podría hallarse coordinado con un préstamo como complemento de pagar. Y, desde luego, la ambigüedad aumenta si se incorporan otros constituyentes "intermedios" dependientes de otros elementos: He pedido un préstamo para pagar unas vacaciones que me tomé cuando tuve que asumir el negocio y una hipoteca.

Puede colegirse, pues, que la disposición de los constituyentes reviste cierta importancia cuando, como sucede en los textos jurídicos y, desde luego, en las sentencias analizadas, las coordinaciones forman parte de "oraciones párrafo" en las que abundan las subordinaciones y los incisos que rompen la linealidad de la construcción, e incluso el hilo argumentativo, y dificultan, cuando menos, "la apreciación de las relaciones entre sus partes" "por culpa del alejamiento de las frases" (Alcaraz y Hugues, 2002: 115).

A veces, la complejidad de las oraciones tiene únicamente como consecuencia que los miembros de las estructuras coordinadas queden separados (al menos, en lo que concierne al primer nivel) por otras construcciones complejas que establecen entre ellos una notable

39 Al margen, claro está, de la que tiene en los casos en que el orden de las coordinaciones siguen el orden de los acontecimientos denotados, reflejan "situaciones reales en el espacio" (Bobes, 1972: 308) u otros aspectos pertinentes en el plano semántico.

40 Según indicaba Givón, por ejemplo, el principio cognitivo de 'proximidad' implica que "entities thar are closer together functionally, conceptually or cognitivley will be piaced closer together at the code level" (1995: 51); de manera que "it is easier to associated mental entities that should be closely associated if they are coded in close temporal (and spatial?) proximity". 
distancia, lo cual, en el mejor de los casos, obliga a releer el texto, "contra todo principio de economía y funcionalidad comunicativa" (Alcaraz y Hugues, 2002: 115), para saber a qué se enlaza realmente el elemento precedido por el coordinador.

Por ejemplo, se habrá de conceder que, en una primera lectura, no resulta fácil apreciar con qué elemento se coordina en el siguiente texto la frase $y$ otras de indole penal, puesto que el contexto inmediatamente precedente no existe ninguna otra expresión nominal con la que se pueda enlazar formando una construcción coordinada:

(20) [...] ni siquiera se han concretado, dados los términos generales en los que aparecen relatados los hechos en el informe del actor obrante en el expediente administrativo, que en caso de haberse probado podrían haber desencadenado una serie de consecuencias jurídico administrativas en punto a la provisión de la plaza, pero que según alegó la parte actora el concurso finalizó (sic) sin que nadie lo impugnase, y otras de indole penal, en el caso de que las amenazas fueran constitutivas de infracción penal o civil... (1927/03)

Es preciso releer el texto para poder interpretar que se une a consecuencias juridico administrativas y que se refiere, por tanto, a la serie de consecuencias que, "de haberse probado" los hechos, se "podrian haber desencadenado".

No obstante, el "alejamiento" de los elementos coordinados, que atenta "contra todo principio de economía y funcionalidad comunicativa", se combina a menudo con esa ambigüedad asociada a la interposición de incisos u otras unidades "subordinadas" que incorporan constituyentes estructuralmente paralelos a los miembros de la coordinación; que diversifican, en consecuencia, las posibles lecturas sintácticas y se convierten en un factor perturbador de la eficacia comunicativa.

Véase, por ejemplo, el siguiente textos:

(21) En el recurso de amparo núm. n, promovido por don [X,] representado por el Procurador de los Tribunales don [Y] y bajo la dirección del Letrado don [Z] contra la Sentencia de la Sala Civil y lo Penal del Tribunal Superior de Justicia de la Comunidad Autónoma del País Vasco de 26 de junio de 1997, recaída en el rollo de apelación núm. 2/97, que estima el recurso de apelación interpuesto contra la Sentencia del Tribunal del Jurado constituido en la Sección Primera de la Audiencia Provincial de Guipúzcoa de 10 de marzo de 1997, recaída en el rollo núm. 1002/96, sobre delitos de asesinato y atentado, y contra la Sentencia de la Sala de lo Penal del Tribunal Supremo núm-364/1998, de 11 de marzo, recaída en el recurso de casación núm. 2381/98, que declaró no haber lugar al recurso de casación interpuesto contra la Sentencia de apelación (TC 246/2004)

Atendiendo al orden lineal y a la composición de los constituyentes, un lector no especialista podría entender - al menos, nada lo impide en el plano gramatical- que contra la Sentencia de la Sala de lo Penal del Tribunal Supremo forma una construcción coordinada con contra la Sentencia del Tribunal del Jurado como complementación alusiva al contenido del recurso de apelación interpuesto; sin embargo, de la lectura $-\mathrm{y}$ relectura - del texto completo se infiere que contra la Sentencia de la Sala de lo Penal del Tribunal Supremo no se enlaza con ese constituyente sino con contra la Sentencia de la Sala Civil y lo Penal del Tribunal Superior de Justicia de la Comunidad Autónoma del País Vasco, como complementos alusivos al contenido del recurso de amparo promovido por don $[X]$. 
En el texto que se incluye a continuación, no solo la oración que se acepte el traslado se halla bastante alejada de las oraciones sustantivas precedentes a las que puede estar enlazada, sino que también, tomando como base su "constitución", podría estar coordinada con que se dictara sentencia, como otra de las acciones "solicitadas", o con que fuera reconocido el acoso moral, como otra especificación del "sentido" de la "sentencia estimatoria de la demanda":

(22) [...] solicitando que se dictara sentencia estimatoria de la demanda en el sentido de que fuera reconocido el acoso moral en el trabajo ocasionado por $\mathrm{D}^{\mathrm{a}}[\mathrm{X}]$, Directora del Departamento [...], junto con $\mathrm{D}^{\mathrm{a}}[\mathrm{Y}],[\mathrm{Z}]$ y $[\mathrm{W}]$, a $\mathrm{D}^{\mathrm{a}}[\mathrm{V}]$, obligando a dichas personas al cese de las conductas de hostigamiento periódico y sistemático que realizan a la Sra. [V] y al abono por los daños morales sufridos por la Sra. V por las conductas anteriormente descritas como acoso moral en el trabajo por $\mathrm{D}^{\mathrm{a}}[\mathrm{X}]$, directora del Departamento [...], junto con $[\mathrm{Y}],[\mathrm{Z}]$ y $[\mathrm{W}]$, en una indemnización que actualmente se cuantifica en 18.030 euros (DIOCIOCHO MIL TREINTA EUROS) y que se acepte el traslado de... (128/03)

Parece "natural" que se una a la oración más próxima, que fuera reconocido el acoso moral en el trabajo, con la que formaría, por tanto, el complemento de "el sentido" en que se ha de concretar la "sentencia estimatoria de la demanda". Pero lo cierto es que, como ya se vio anteriormente, no siempre un elemento precedido de marca de coordinación se enlaza con el constituyente potencialmente "equivalente" más próximo, sino con otro más alejado, con lo que, al menos en una primera lectura, este enunciado puede resultar confuso.

Tampoco queda claro en el siguiente texto qué elementos va enlazando el coordinador asi como, con significado copulativo de "suma" como $y$, pero más "marcado", según antes se dijo, porque conlleva una organización binaria y una interpretación de carácter distributivo:

(23) La Administración demandada se opuso a las pretensiones de la parte actora y, solicitando la desestimación de la demanda, alegó la conformidad a Derecho del acto administrativo impugnado, a lo que se adhirieron los codemandados, negando la existencia de los hechos alegados por la actora, así como la condena en costas a la recurrente por su temeridad y mala fe $(128 / 2003)$.

La ordenación sintáctica nos llevaría a enlazar la condena en costas - una expresión nominal sin preposición, como es característico de los objetos directos- con la existencia de los hechos alegados, el objeto directo de negando, pero, a la vista del contexto, no parece tener mucho sentido que ambas expresiones se sumen como objeto afectado por negando: ¿Se niega la existencia de los hechos y la condena en costas? La interpretación parece asimismo extraña si se une a la conformidad para configurar el conjunto objeto del verbo "alegar". Tal vez pueda entenderse unido a la desestimación como objeto de solicitando: solicitando la desestimación de la demanda, así como la condena en costas a la recurrente. Pero, en ese caso, habrá de concederse que la construcción sintáctica del párrafo resulta claramente inadecuada: la separación de los constituyentes coordinados en el primer nivel no vendría dada por subordinaciones o"incisos" sino por la oración "principal" (alegó la conformidad...) de la que depende la construcción de gerundio. 
En el texto que se incluye a continuación, es asimismo difícil determinar cuál es el conjunto coordinado del que forma parte la oración que ninguna objeción se ha puesto, y no solo por la existencia de otras oraciones sustantivas, dependientes de núcleos distintos, en el contexto discursivo anterior:

(24) Ha señalarse que, como alegó la representación procesal de la parte codemandada, consta en el expediente administrativo (...) que la Comisión fijó los criterios de valoración en el Anexo a su reunión convocada a tal efecto (folio $\mathrm{n}^{\circ} 8$ ), hemos (sic) de subrayar que, si bien estamos ante una infracción al procedimiento establecido en el Real Decreto de aplicación, no es menos cierto que dicha infracción no puede considerarse sino como meramente formal pues en ningún momento ha causado perjuicio a ninguno de los aspirantes presentados al concurso, como lo prueba el hecho de que ambos superasen el primer ejercicio (documento $\mathrm{n}^{\circ} 8$ ), y que ninguna objeción se ha puesto en este sentido por el testigo que actuó como Vocal Segundo en las pruebas selectivas (16/03).

El uso del modo indicativo parece un indicador de que la coordinación se establece con otra sustantiva también en indicativo:

a) Podría formar con que dicha infracción... una construcción coordinada sujeto del predicado asertivo es cierto: no es menos cierto cc((que dicha infracción no puede considerarse...) 1 y (que ninguna objeción... $\left.)_{2}\right)_{\mathrm{cc}}$.

b) O podría coordinarse con la oración sustantiva del nivel superior, no es menos cierto... para formar el conjunto complemento directo de hemos de subrayar: hemos de subrayar cc((que no es menos cierto...) $)_{1}$ y (que ninguna objeción se ha puesto...) 2 ) cc.

En cambio, tanto la coma que precede a la oración, como el hecho de que no se haya utilizado el modo subjuntivo, induce a rechazar la interpretación que, haciendo abstracción de esos rasgos, quizá resultaría más natural: la que nos llevaría a coordinar que ninguna objeción se ha puesto con la oración sustantiva en subjuntivo inmediatamente anterior (que ambos superasen el primer ejercicio) para denotar el conjunto de "hechos" que "prueban" que "a los concursantes no se les ha causado ningún perjuicio". Pero, de hecho, no se puede descartar que ese sea precisamente el sentido pretendido por el redactor y que, simplemente, no se haya hecho un buen uso de la puntuación, ni la selección del modo haya sido la más adecuada para "realzar" la equivalencia, en lo que concierne al carácter factivo"1, de las oraciones sujeto del verbo evidencial "probar".

\subsection{Las formas verbales en la coordinación de oraciones subordinadas}

En realidad, si a veces los textos jurídicos evidencian cierta "despreocupación"42 por el uso de los signos de puntuación, tampoco son inusuales en las sentencias analizadas las formas verbales incorrectas o, cuando menos, extrañas, de manera que no siempre las formas

41 De conformidad con Delbecque y Lamiroy (1999: 2002), la interpretación factiva del sujeto seleccionado por un verbo "evidencial", como sería el caso de "probar", se puede "realzar" mediante el sintagma el hecho de que, asociado, como el subjuntivo, a la presuposición y la "factividad". Ha de tenerse en cuenta, no obstante, que la expresión el hecho de que no impone sobre la sustantiva "restricciones gramaticales" (Leonetti, 1999: 2100).

42 Samaniego (2005: 300), por ejemplo, achaca esa despreocupación al hecho de que "las cuestiones estilísticas se consideran secundarias, y se da prioridad absoluta al contenido", si bien es obvio que la puntuación también es una "marca" de contenido. 
verbales (el uso del infinitivo o de un verbo finito en indicativo o en subjuntivo) se pueden tomar como indicio de que dos o más oraciones subordinadas se integran, como miembros de una coordinación, en una determinada posición sintáctica.

Así, por ejemplo, aunque es posible, con ciertas restricciones (Camacho, 1999: 2641), coordinar oraciones en infinitivo con oraciones con verbo finito, como se hace en el texto que se reproduce más abajo, parece claro que el uso del infinitivo en la primera oración sustantiva dependiente de suplica implica una correferencialidad, tal vez no deseada, entre el sujeto léxico de suplica y el sujeto lógico de anular (Hernanz, 1999: 2278); es decir, al haberse utilizado el infinitivo, se debería interpretar que es la parte demandante, la misma que suplica, la que está en disposición de "anular", algo que no parece muy acorde con el papel que le corresponde a las partes demandantes en las relaciones jurídicas:

(25) Suplica la parte demandante:

$1^{\circ}$ Anular por ser disconforme a Derecho la resolución que se impugna [...]

$3^{\circ}$ Que se reconozca como situación jurídica individualizada el derecho a que [...] se proceda a una nueva valoración y revisión de la calificación obtenida [...] (122/2003).

Puesto que quien tiene capacidad para "anular" es el "complemento indirecto implícito" (Hernanz, 1999: 2278) del verbo de influencia suplica, debería haberse utilizado el modo subjuntivo como en que se reconozca como situación jurídica...

En el texto que se incluye más abajo, simplemente no se puede deducir con qué oración "dependiente" se coordina la oración de infinitivo precedida de la conjunción copulativa; ni por el sentido ni por las formas verbales podría estar coordinada con la oración final inmediatamente precedente, ni tampoco, naturalmente con por la que se desestimó..., una oración adjetiva explicativa.

(26) Es objeto del presente recurso contencioso-administrativo la Resolución del Vicerrector de Ordenación Académica y profesorado de la Universidad de Alicante, de 16 de septiembre de 2002, por la que se desestimó la solicitud de la actora para que se reconozca que ha sufrido acoso moral por parte de los Profesores X, Y, Z, y W y, en consecuencia, ordenar el cese de la instrucción del expediente de responsabilidad patrimonial incoado ante la petición de indemnización contenida en la mencionada solicitud (128/03)

En este otro texto:

(27) [Invocando como motivos de impugnación] falta de motivación de la resolución que recoge la propuesta de provisión a que se refiere el art. 11 del RD 1888/1984 y en relación con el voto de D. [...] que en el informe previo se remite a después de realizadas las pruebas y no constar su opinión en el informe conjunto más que de forma vaga e imprecisa $(321 / 04)$.

resultaría inadecuado el infinitivo constar si lo que se pretendía era coordinar esa oración sustantiva con la inmediatamente precedente que en el informe previo se remite... como objeto del verbo de comunicación "invocar"43. 
Por último, en el siguiente texto tampoco el uso de las formas verbales permite deducir con claridad con qué se une, mediante la conjunción copulativa $n i$, la oración organizada en torno a se exteriorizan:

(28) Considera que no ha quedado probada y que dificilmente puede mantenerse cuando el acuerdo sobre la propuesta del perfil de la nueva plaza se efectuó en secreto y por unanimidad de los veinte miembros del Consejo, sin que tampoco haya quedado probada la enemistad con los miembros del Tribunal propuestos, que no se concreta en ningún miembro ni se exteriorizan los motivos en que la actora se fundamenta para alegar dicha enemistad $(777 / 2003,5$

Dado que se exteriorizan es una construcción pasiva refleja, de agente indeterminado, y que no se concreta es una oración adjetiva cuyo sujeto que nos remite a la enemistad, no se puede interpretar que esté coordinada con no se concreta..., aunque no medie entre las dos oraciones una pausa. Puede entenderse más bien que se coordina con haya quedado probada la enemistad, pero, en ese caso, además de que la oración adjetiva debería estar enmarcada por comas, sería anómalo el uso del indicativo exteriorizan. Como requeriría el "inductor negativo fuerte" (Sánchez López, 1999: 2617) del que dependería la construcción coordina$\mathrm{da}$, debería utilizarse el subjuntivo, ni se exterioricen - o ni se hayan exteriorizado-, como en haya quedado probada, el otro miembro de la estructura copulativa.

Es preciso reconocer, por tanto, que si bien el uso del infinitivo o la selección del modo indicativo o subjuntivo en las oraciones subordinadas se asocia a su papel sintáctico-semántico, a las restricciones que imponen los núcleos, y puede formar parte, por tanto, de la equivalencia o el paralelismo (en algunos aspectos) que se requiere en los constituyentes coordinados, su carácter de "signo positivo" para la lectura de la coordinación puede verse considerablemente mermado cuando en un texto se emplean con "descuido" o de un modo poco sistemático.

\subsection{La coordinación de nominalizaciones y oraciones}

A lo largo de este trabajo se ha venido haciendo referencia al "paralelismo" "in certain respects", a la "analogia" o "equivalencia" "in some sense" que las características generales de la coordinación imponen sobre los elementos coordinados, así como al papel que, debido a esa exigencia, desempeña la composición interna de los constituyentes tanto en el procesamiento de las coordinaciones como en la ambigüedad estructural. De hecho, en los casos de lectura "costosa" o de ambigüedad que se han ido comentando hasta ahora todos los constituyentes implicados eran realmente "paralelos" desde el punto de vista categorial: eran todos sintagmas preposicionales introducidos por la misma preposición (como en (18) y en (21)), todos sintagmas nominales (como en (20) y en (23)), o todos oraciones, como en (22), (24), (25), (26), (27)y (28).

Ha de recordarse, no obstante, que la "equivalencia" o "paralelismo" de los miembros de la coordinación no implica que, según se planteaba en los estudios generativistas hace años,

comunicación, "suelen excluir dicha forma no personal", aunque la alternancia indicativo/ infinitivo sea aceptable en casos concretos en que "la subordinada aporta elementos capaces de neutralizar la ambigüedad temporal" (1999: 2288). 
"only identical categories can be conjoined" (Radford, 1988: 76) 4 . Como ha sido "múltiples veces constatado" (Bosque, 1987: 84), es posible la coordinación heterocategorial ${ }^{45}$ siempre que los elementos enlazados presenten "compatibilidad distribucional" (Brucart, 1987: 106), que cada uno de ellos tenga una categoría y un contenido semántico adecuado a la "función", al "nivel", en que se integra la construcción coordinada ${ }^{46}$. De ahí que, según señalaba Borsley (2005: 465), "how similar conjuncts must be depends on the context on which coordinate structure appears, specifically on how specific the constraints that it imposes on constituents occupying the position of the coordinate structure are".

No es, pues, necesario que las expresiones nominales incluidas en una construcción coordinada con función de sujeto o de objeto directo sean todas oraciones sustantivas o todas sintagmas nominales. Como indica Camacho (1999: 2641), por ejemplo, es posible ${ }^{47}$, coordinar nombres deverbales designadores de eventos, nominalizaciones, tan abundantes en los textos jurídicos ${ }^{48}$, con oraciones sustantivas: Odio las llegadas de Secundino y que Cecilia siempre se niegue a verlo, Me molestó la llegada de los invitados y tener que organizar la fiesta.

No es infrecuente, en efecto, que en las sentencias analizadas las coordinaciones estén integradas por nominalizaciones y oraciones sustantivas ${ }^{49}$. En el siguiente texto, una nominalización (la fijación de unos criterios...) y una oración sustantiva (que dicho juicio se plasme...) forman el sujeto coordinado de cabiendo:

44 Tal requisito ha figurado en las definiciones de coordinación ofrecidas por algunos diccionarios. Así, en el diccionario de términos gramaticales de Trask (1993), se dice que "in a typical coordinate structure, all of the conjoined constituents (the conjuncts) are of the same category, and the whole structure is an instance of the same category". Más recientemente, Berry, Kamstie y Krieger (2003: 46), por ejemplo, también afirman que "in phrases connected by a conjuction, each of the phrases should be of the same part of speech, e.g. all nouns, all verbs, etc. More that that within the part of speech, each should be of the same grammatical structure".

45 Aunque como señalaban, por ejemplo, Schachter (1977) y Haspelmath (2000) hay lenguas que, en ciertos casos, sí requieren "identidad".

46 Come despacio y sin apetito (Bosque, 1987: 84), Es un hombre agradable y de buen corazón, por ejemplo, son construcciones correctas a pesar que los constituyentes coordinados no son categorialmente idénticos: despacio (adv.) y sin apetito (sprep.) están capacitados para asumir la función de complemento modal; agradable (adj.) y (de buen corazón), se sitúan en el "mismo nivel" del sintagma nominal dado que también se igualan en lo que concierne a su aportación semántica. No obstante, no pasa desapercibido que los conceptos tales como 'función sintáctica' - 'papel semántico' resultan controvertidos. Tampoco el concepto de 'nivel jerárquico', asociado a la equivalencia semántica, se halla libre de problemas, puesto que remite a cuestiones complejas como la jerarquización de los posibles complementos del nombre.

47 Aun cuando no estén completamente especificados los factores que influyen en la mayor o menor aceptabilidad de esta clase de coordinaciones. Camacho afirma que "si el contexto facilita la posibilidad de interpretar los dos elementos coordinados como eventos separados, las oraciones resultan más aceptables"; asimismo añade: "los verbos del tipo gustar; temer (sic), molestar; sorprender, etc., en los que lo gustado, temido, etc., aparece como sujeto y el que teme, gusta, etc., como objeto, permiten interpretar los nombres eventivos con mayor facilidad" (1999: 2642).

48 Las oraciones, según Camacho (1999: 2641), también pueden combinarse con otros tipos de nombres si el contexto posibilita su interpretación como eventos.

49 Es una combinación frecuente cuando, por ejemplo, se detallan los cargos imputados o se enumeran las acciones que se solicitan: "Suplica la parte demandante a) la anulación de las resoluciones rectorales (...) d) que se condene en costas a la Administración demandada (79/05); Se imputan a la actora los siguientes cargos: (...) b) intromisión en la actividad docente (...) d) realizar actuaciones conminatorias (...)" (161/03), 
(29) Por lo que respecta a los procedimientos selectivos o competitivos de cualquier tipo, el problema o la cuestión más esencial no radica en el modo concreto de motivar, sino en las bases o fundamentos de tal modo de proceder, cabiendo, así, la fijación de unos criterios o parámetros de referencia por comparación con los cuales se juzgue cada caso y que dicho juicio se plasme, por ejemplo, en una puntuación o en un voto decisorio (311/04).

En este otro se detallan mediante una construcción integrada por una nominalización y dos oraciones sustantivas las otras circunstancias concurrentes que llevan "a la juzgadora de instancia" a inferir "lo que pudo suceder":

(30) Así en el presente supuesto, entendía la Audiencia, existían versiones contradictorias lo que había llevado a la juzgadora de instancia ala inferencia de lo que pudo suceder, a través de otras circunstancias concurrentes como la inexistencia de denuncias previas sobre hechos similares, situarse en el ámbito de una crisis matrimonial y haber entregado a la Guardia Civil la escopeta (TC 65/05)

En el siguiente, por último, una nominalización (la inadmisión a trámite de la demanda) y una oración sustantiva (que se dirigieran atentas comunicaciones...) se hallan coordinadas como complemento de se acordó:

(31) Se acordó la inadmisión a trámite de la demanda, y en aplicación de lo establecido en el art. 51 LOTC que se dirigieran atentas comunicaciones a la Sección Decimoséptima de la Audiencia Provincial de Madrid (TC 65/05)

Por tanto, esta combinación de nominalizaciones y oraciones sustantivas, tan frecuente en las sentencias o en otros tipos de textos jurídicos, puede ser inobjetable en lo que concierne al cumplimiento de condiciones gramaticales. Pero, si el paralelismo estructural, en un primer nivel, se erige en referencia básica (aunque no siempre suficiente) para la lectura de las coordinaciones, especialmente si está formadas por elementos "largos y complejos", se habrá de conceder que la coordinación de constituyentes no paralelos en su constitución, como las oraciones y los sintagmas nominales, puede contribuir a incrementar el "coste" de la lectura o el riesgo de ambigüedad estructural ${ }^{50}$.

Véase, por ejemplo, el siguiente texto:

(32) La parte demandada alegó que la documentación aportada es irrelevante en el presente recurso, pues no guarda relación con ninguno de los argumentos de la demanda, ya que de los listados remitidos por la Universidad se desprende la objetividad de la Comisión Evaluadora, que calificó la realización de los cursos con una puntuación numérica y concreta y que la valoración de los cursos de formación de cada uno de los aspirantes no puede

50 Considérese, por ejemplo, el siguiente enunciado: He solicitado que se acepte el escrito y que se repita la votación. No es en absoluto ambiguo porque la estructura de los complementos correspondientes a "solicitado" -dos oraciones sustantivas encabezadas por que - nos lleva inequívocamente a enlazarlos como constituyentes que dependen de he solicitado y que tienen "el mismo estatus". Si sustituimos, en cambio, la segunda oración sustantiva por una nominalización, He solicitado que se acepte el escrito y la repetición de la votación, el enunciado se convierte en ambiguo porque, por la forma de los constituyentes, la repetición de la votación podría coordinarse también con el sintagma nominal precedente, el escrito, e interpretarse, por tanto, como complemento de se acepte. 
ser objeto de revisión, ya que estos criterios se encuentran dentro del denominado ámbito de la discrecionalidad técnica, al que antes se hizo alusión (137/03)

Tal vez podríamos entender que la oración que la valoración de los cursos... Se enlaza con el sintagma nominal la objetividad de la Comisión Evaluadora como sujeto coordinado de se desprende. No obstante, también cabe interpretar que la oración encabezada por que se coordina con la causal, $(y a)$ que de los listados remitidos, o con que la documentación aportada es irrelevante, la oración más "distanciada", como parte de lo "alegado" por "la parte demandada". Es, pues, una construcción ambigua, porque, por un lado, hay más de una oración "candidata" a formar con que la valoración de los cursos... el conjunto coordinado; por otro lado, el hecho de que en este tipo de textos resulte habitual la coordinación entre oraciones y sintagmas nominales, hace que se incorpore a las posibles lecturas otro nivel más.

También el siguiente texto ofrece varias pautas de interpretación atendiendo a la posibilidad de que las oraciones se combinen no solo con otras oraciones, sino también con sintagmas:

(33) La parte demandada invoca como causas de inadmisibilidad, la incompetencia territorial, resuelta con carácter previo en el acto de juicio al ser desestimada a la vista de la inexistencia de pluralidad de destinatarios al haberse presentado a la realización de las pruebas únicamente la recurrente, e impugnarse actos firmes y consentidos, en base a no haber la recurrente recusado en su momento a los miembros de la comisión (321/04)

Tomando como referencia el paralelismo en la estructuración interna, la oración en infinitivo impugnarse actos firmes y consentidos puede entenderse enlazada con (al) haberse presentado a la realización de las pruebas únicamente la recurrente, la oración en infinitivo, de carácter causal, que le precede de forma inmediata. Pero, por otro lado, podría ser una oración sustantiva coordinada con el sintagma la incompetencia territorial como una de las "causas de inadmisibilidad" invocadas por "la parte demandada".

$\mathrm{Si}$, por último, consideramos el siguiente texto:

(34) En caso de estimar exclusivamente el segundo motivo de impugnación, el referido a las supuestas presiones, que se declare nulo el concurso de la plaza C 982, apartando de la Comisión Evaluadora al o los integrantes de la misma que en el presente plenario quede acreditado, en su caso, que sucumbió o sucumbieron a presiones para favorecer al otro candidato, o que ejerció o ejercieron presiones para favorecer al otro candidato, y la celebración de nuevas pruebas (16/03)

se habrá de admitir que, en una primera lectura, no resulta sencillo dilucidar con qué se une la celebración de nuevas pruebas. Ha de releerse el texto para entender que se une a la oración sustantiva que se declare nulo el concurso de la plaza C982 como objeto de un predicado de influencia que figura en un párrafo anterior y da paso a la serie de acciones solicitadas en la demanda. Dejando al margen otros aspectos sintácticos, al menos habría resultado menos costosa la interpretación si se hubiera utilizado otra oración sustantiva, que se celebren nuevas pruebas, paralela en su estructura a la anterior, en lugar de una nominalización. 


\section{Para concluir}

Sin duda, las coordinaciones que se dan en las sentencias, como en otros tipos de géneros jurídicos, ofrecen muchos puntos de interés para el análisis lingüístico: no es inusual, por ejemplo, el uso de $y$ como conector de enunciados, en cuya interpretación intervienen factores pragmáticos aún no bien sistematizados; tampoco son extrañas, en la coordinación de constituyentes, las ambigüedades relacionales o las ambigüedades semánticas vinculadas a las posibilidades de interpretación distributiva o colectiva; menudean, además, las coordinaciones extrañas o claramente incorrectas que constituyen una buena fuente de datos para profundizar en los requisitos de la "coordinabilidad"s1.

En este trabajo, como se planteaba al principio, se ha tratado únicamente un aspecto, quizá el más simple, de las construcciones coordinadas que pueden encontrarse en las sentencias: su potencial como fuente para ciertos tipos de ambigüedad estructural asociados a los constituyentes complejos que incorporan complementaciones y coordinaciones en distintos niveles, o a las coordinaciones múltiples cuyos miembros pueden estar, a su vez, integrados por coordinaciones.

Seguramente se podrían haber expuesto más "casos", aunque no parecía aconsejable por razones de espacio. Pero tal vez los ejemplos utilizados hayan bastado para justificar que, como se dijo al principio, la coordinación, ese procedimiento "simple", de "alto rendimiento estructural", asociado a la sencillez y a la claridad expositiva, pero también "insuficiente y ambiguo" "al nivel formal" (Bobes, 1972: 286), puede no ser precisamente "garantía de inteligibilidad" cuando se combina con esas tendencias constructivas que, según los estudios especializados, dominan en los textos jurídicos. Esto es, cuando las construcciones coordinadas forman parte de "párrafos largos" en los que abundan las nominalizaciones, las oraciones intrincadas, los "sintagmas nominales largos", con abundancia de complementos y subordinaciones que multiplican los candidatos a formar parte de una estructura coordinada; cuando abundan los incisos que desencadenan rupturas de la construcción y hacen que se pierda el hilo argumentativo; cuando, además, los otros "indicadores" lingüísticos" - las formas verbales, el orden, las marcas de función, la puntuación...- no se someten a un uso sistemático o resultan poco cuidados, o su papel como guía para el procesamiento se ve afectado por incorrecciones de construcción. Cuando, por último, el papel "neutralizador" de la ambigüedad que desempeñan el "sentido común", las presuposiciones, los "saberes" compartidos por el emisor y el destinatario de la comunicación, se ve anulado porque, como puede ocurrir en el caso de las sentencias, el texto ha de ser interpretado por un "ciudadano común", un lector "no especializado" que, según señalaba De Miguel (2000), no suele contar como "receptor real" en los planes del "emisor especializado".

51 Véase, por ejemplo, el uso de $y$, calificado como "expletivo", para coordinar complementos nominales que, en reatidad, deben estar "jerarquizados": "FALLO: Que estimando la demanda interpuesta por X frente a Universitat D'Alacant debo declarar y declaro improcedente el despido de la actora $y$ producido por el Organismo demandado en fecha 13 de septiembre de 2004" (802/04), "[...]así como que se habían causado los daños que se relacionan en el Hecho Segundo de la demanda: actuación que estaba siendo realizada por operarios de la empresa $[\mathrm{X}]$ y que estaban realizando unos trabajos para la Universidad de Alicante" (109/05). 


\section{Referencias bibliográficas}

Alcaraz Varó, E. y B. Hugues (2002): El español juridico. Barcelona, Ariel.

Berry, D. M., Kamsties, E. y M. M. Krieger (2003): From contract drafting to software specification: Linguistic Sources of Ambiguity, http://www.se.uwaterloo.ca/dberry/handbook/ambiguityhandook.

Bobes Naves, M. C. (1972): "La coordinación en la frase nominal castellana", RESEL, 2, págs. 285311.

Borsley, R. P. (2005): "Against ConjP", Lingua, 115, págs. 461-482.

Bosque, I. (1987): "Constricciones morfológicas sobre la coordinación”, $L E A$, IX, 1, págs. 83-100.

Bosque, I. y V. Demonte (dirs.) (1999): Gramática Descriptiva de la Lengua Española, Madrid, Espasa.

Brucart, J. M. (1987): "Sobre la representación sintáctica de las estructuras coordinadas", RSEL; 17 , págs. $105-129$.

Camacho, J. (1999): “La coordinación”. En Bosque, I. y V. Demonte (dirs.): págs. 2635-2694.

Camacho, J. (2004): The Structure of Coordination. Dordrecht, Kluwer.

Carston, R. y D. Blakemore (2005): "Introduction to Coordination: Syntax, Semantics and Pragmatics", Lingua, 115, págs. 353-358.

Cormack, A. y N. Smith (2005): "What is coordination?", Lingua, 115, pags. 395-418.

Delbecque, N. y B. Lamiroy (1999): "La subordinación sustantiva: Las subordinadas enunciativas en los complementos verbales". En Bosque, I. y V. Demonte (dirs.): págs. 1965-2081.

De Miguel, E. (2000): "El texto jurídico administrativo: análisis de una Orden Ministerial", Revista de Lengua y Literatura españolas, 2, págs. 6-31.

Dik, S. C. (1968): Coordination. Its implications for the Theory of General Linguistics. Amsterdam, North Holland.

Dik, S. C. (1997): The Theory of Functional Grammar, 2. Berlin-New York, Mounton.

Franchini, E. (1986): Las condiciones gramaticales de la coordinación copulativa en español. Berna, Francke Verlag.

Givón, T. (1995): "Isomorphism in the Grammatical Code". En Simone, R. (ed.): Iconicity in Language. Amsterdam, Philadelphia, John Benjamins.

Gómez Torrego, L. (1997): Gramática didáctica del español. Madrid, SM.

Haspelmath, M. (2000): "Coordination", En Shopen, T. (ed.): Language Typology and linguistic description. Cambridge, CUP, http:/www.era.mpg.de/haspelmt/coord.

Hernanz, M. LL. (1999): "El infinitivo". En Bosque, I. y V. Demonte (dirs.): págs. 2197-2356.

Jiménez Juliá, T. (1995): La coordinación en español. Aspectos teóricos y descriptivos. Verba, anexo 39, Santiago de Compostela, Universidade de Santiago de Compostela.

Langacker, R. (1991): Foundations of Cognitive Grammar, II. California, Stanford.

Leonetti, M. (1999): "La subordinación sustantivia: Las subordinadas enunciativas en los complementos nominales". En Bosque, I. y V. Demonte (dirs.): págs. 2083-2104.

Radford, A. (1988): Transformational Grammar. Cambridge, Cambridge University Press.

Real Academia Española (1973): Esbozo de una nueva gramática de la lengua española. Madrid, Espasa.

Samaniego Fernández, E. (2005): "El lenguaje jurídico: peculiaridades del español jurídico". En Fuertes Olivera, P. (ed.): Lengua y sociedad en los albores del siglo XXI. Valladolid, Universidad.

Sánchez López, C. (1999): “La negación”. En Boque, I. y V. Demonte (dirs.): págs. 2561-2634.

Schachter, P. (1977): "Constraints on coordination", Language, 53, págs. 86-103.

Trask, R. L. (1993): A Dictionary of Grammatical Terms in Linguistics. London and New York, Routledge. 